\title{
Prevalence and Causes of Maternal Mortality in Ekiti State, Nigeria
}

\author{
DR KONWEA, Patience Esohe \\ B.Sc (Benin), M.Ed (Benin) Ph.D (Ibadan) \\ FABAMISE, OLUFEMI MOSES \\ B.Sc. (Ilorin), PGDE (Ado-Ekiti), M.Sc (Ado-Ekiti)
}

\begin{abstract}
Maternal mortality has become a global issue attracting attention from governmental and Non-governmental organizations. In the light of this, this study investigated prevalence and causes of maternal mortality in Ekiti State. The study was a descriptive research design of the survey type. The population for the study comprised of all the 66 Doctors and 588 Nurses in the 20 general and specialist hospitals in Ekiti State. The sample for the study consisted of 60 doctors and 490 nurses who were selected using random sampling and proportionate sampling techniques. Data were collected with the use of a structured questionnaire titled: Cases and Causesof maternal mortality (CCMM). The reliability of the instrument was estimated using test- retest method with the reliability coefficient of 0.74 obtained. The data collected were analyzed using the descriptive statistics of frequency counts, simple percentages and mean for the general questions and inferential statistics of Pearson's Product Moment Correlation for the hypotheses. All hypotheses were tested at 0.05 level of significance. The findings of the study showed there was high maternal mortality cases in Ekiti state and it is as a result of poor educational status and early marriage with early pregnancy. It was therefore recommended that more awareness should be created on the causes of maternal mortality by the government, NGOs and other health regulated agencies, hence reducing this menace of maternal death. Pregnant women should be educated by health workers on how successfully handle pregnancy related cases during complications and adolescent should be orientated on the consequences of early pregnancy since they are the most victims of maternal cases.
\end{abstract}

DOI: $10.7176 / \mathrm{JHMN} / 64-06$

Publication date:July $31^{\text {st }} 2019$

\section{Introduction}

Pregnancy and child bearing are supposed to be a pleasant experience to women but the constant scourge of complications and death associated with it have indeed turned the stage to be a nightmare to women so much so that hundreds of potential mothers have been sent to their early graves. Maternal mortality has been observed to be one of the major causes of death among women of reproductive age in many countries and remains a serious public health issue especially in developing countries. Maternal mortality refers to deaths due to complications from pregnancy or childbirth. It has also been described as the death of a woman while pregnant or within 42 days of termination of pregnancy, irrespective of the duration and site of the pregnancy, from any cause related to or aggravated by the pregnancy or its management but not from accidental or incidental causes (Shah \& Say 2007).

The Bamako Initiative (BI) programme in 2013 reported that Nigeria had one of the highest maternal mortality rates in the world and this necessitated the greater attention given to Maternal and Child Health (MCH) services in the country by the Bamako Initiative. The statistics about the situation in Nigeria as reported by the World Health Organisation in Nursing Nigeria World 2013 is disturbing having reported that that at least six women die during child birth or shortly after every hour, yet the target date of 2015 for reducing maternal mortality by $75 \%$ had gone unachieved.

It appears that some of the contributory factors to maternal mortality in Nigeria include malnutrition, poor environmental hygiene, low access and utilization of quality health care services by women and literacy level. Some women seem to be more at risk than others in Nigeria. For instance the rural dwellers due to their less privilege and access to medical services may be more prone to complication and situation that leads to maternal mortality. Inability to have prompt treatment for some medical cases such as ante partum or post partum hemorrhage, post-delivery infection, hypertensive disorders in pregnancy and obstructed labour may predispose women to death.

Several attempts have been made in the past to combat the menace of maternal mortality but have yielded results that are less than expected. Some promising results however have been recorded through some policy initiatives by a few state governments. The Ondo State Government initiative known as Abiye, that uses mobile phones to save the lifes of indigent pregnant women in rural communities recorded a level of success. Pregnant women directly contact doctors through designated mobile line when they noticed any related health issues.

Adolescents are often noted to have an increased risk of death during pregnancy or childbirth compared 
with older women, but the existing evidence is inconsistent and in many cases contradictory. The risk of death among young mothers may be influenced by incomplete pelvic growth, leading to a greater probability of obstructed labor, while among older women existing morbidities may complicate pregnancy. Although most women experiencing life threatening obstetrical hemorrhage have no clear risk factors, it tends to be more common among women over 40 and women under 20, although not all studies find age to be a significant risk factor.

Women's lack of education seems to be one of the causes of high maternal mortality in Nigeria. The United Nations Fund For Population Activities (UNFPA) stated that girl-child education is key to reducing increasing cases of Vesico Vaginal Fistula (VVF) in Nigeria. With more educated women, the chances are that more children will be enrolled in schools, as the women are their custodians. It is belief that more educated women would demand for access to ante-natal care and other reproductive health services. This also means that more women would deliver at the health facilities, as such, reduce menace of prolonged labour which often leads to maternal mortality among others.

The issue of maternal mortality in Nigeria has been adduced to both medical and social factors and it is believed that the way to take maternal mortality is to simultaneously deal with these factors .However, while numerous studies have focused on the medical factors that causes maternal mortality, few had worked on the prevalence and causes of maternal mortality especially in Ekiti State. This study therefore examined prevalence and causes of maternal mortality in Ekiti state.

\section{Statement of the Problem}

It has been observed by the researcher that, in spite of all the policies, declarations, conferences and other efforts aimed at reducing the scourge of maternal deaths across the globe, only modest gains in maternal mortality reduction appear to have been achieved in many countries including Nigeria and Ekiti in particular. Although maternal deaths in Ekiti State may be observed to be mainly due to complications of pregnancy and delivery, the conditions under which these pregnancies and deliveries occur may pave way for complications and deaths. Incidentally very few studies have focused exclusively on this aspect.

The number of motherless children in motherless homes is not dwindling but rather increasing day by day. The fear attributed to childbirth by expected mothers in various health facilities as observed in various choruses and hymns rendered during antenatal with the prayers of not dying during childbirth is clearly observed. This study therefore examined prevalence and causes of maternal mortality in Ekiti State.

\section{Purpose of the Study}

The purpose of this study was to examine the prevalence and causes of maternal mortality in Ekiti State. The study examined the cases of maternal mortality in Ekiti. Also, the study is to find out whether age and educational status of women causes maternal mortality in Ekiti.

\section{Research Questions}

The following research questions were raised for the study:

1. To what extent do cases of maternal mortality occur in Ekiti State?

2. Does age of pregnant women contribute to maternal mortality in Ekiti State?

3. Does educational status of pregnant women contribute to maternal mortality in Ekiti State?

\section{Research Hypotheses}

The following hypotheses were tested.

1. There is no significant correlation between age of pregnant women and maternal mortality in Ekiti State.

2. There is no significant correlation between educational status of pregnant women and maternal mortality in Ekiti State

\section{Significance of the Study}

The study would be of great benefit to mothers, health workers, hospital administrators, Government and NonGovernmental Organisations (NGO). Findings from this study could provide information on the socio-cultural practices that could lead to maternal mortality. Understanding and identification of the socio-cultural factors that affect maternal mortality will be of importance to health educators because it will help in designing health education and health promotion programmes to provide right information on maternal mortality during antenatal and postnatal care. It is believed that the outcome of this study will benefit primary health workers to disseminate the right information on maternal health hence reducing mortality.

Finally, this study may also be useful to all stake holders in health sectors, especially non-governmental organizations(NGOs) and policy makers when planning and monitoring health programmes related to maternal health. 


\title{
Age and Maternal Mortality
}

Age is measured in chronological terms beginning at a person's date of birth. The concept of age indicates a structured nature of social relationship whereby interaction is hierarchical. Age connotes the idea of superiority in terms of ability to think and make decisions (Jegede, 1998). Age also determines the readiness of the physiology of the mother. According to Ufford and Menkiti (2001) and the 1999 Nigeria Demographic and Health Survey (DHS), many maternal deaths occur because of early childbearing. Adolescents suffer disproportionately from complications related to childbearing because their bodies are not fully developed (Idowuet al, 2011; Ufford\&Menkiti, 2001). High fertility means women are exposed more often to the risk of maternal death. Galadima, the regional manager of the Abuja-based Society for Family Health (SFH), in Abdul ${ }^{e}$ Aziz (2008) also affirmed that a woman should not start having children too early in life because if a woman's body is not ready to receive pregnancy, there is the likelihood of complications. Definitely the under aged women are more susceptible to maternal morbidity and mortality, according to Graczyk (2007), they are not likely to be able to discuss their reproductive health with their husbands or to seek health care. Early marriage enhances early pregnancy, this thus have harmful consequences of the young mother which often leads to obstructed labour which provokes vesicovaginal fistulas and most often there is increase short birth intervals which may lead to maternal death.

\section{Educational Status and Maternal Mortality}

Education is a factor which offers the possibility of affecting the magnitude of maternal mortality in a number of different ways (Oxaal\& Baden, 1996). The influence of education on health is assumed to derive from various dimensions of the educational experience; schooling imparts literacy skills, which enables pupils to process a wide range of information and stimulate cognitive development (Idowu, Osinaike\&Ajayi, 2011). The knowledge acquired as part of the school curriculum is clearly instrumental for informed decision-making and it largely shapes individual ${ }^{\text {ee }}$ interaction with the surrounding world (Holsinger, 1973). Schools are also important agents of socialization, with a crucial role in shaping attitudes, opinions and values, which serve as a medication against fatalism.

Educated women may have more understanding of the physiology of reproduction and be less disposed to accept the complications and risks of pregnancy as inevitable, than illiterate or uneducated women (Oxaal\& Baden, 1996). As Graczyk (2007) puts it, lack of education can also affect health when it limits young women's knowledge about nutrition, birth spacing and contraception. For instance, as at 2004, 41.6 million Nigerian women had no formal education while 21.4 million had primary education. 31.1 million had secondary education while only 5.9 million had higher education [National Population Commission Nigeria and ORC Macro, 2004).

\section{Methodology}

The descriptive research design of the survey type was adopted for the study. It comprises of all 654 health personnel (Doctors and Nurses) in the seventeen (17) general and three (3) specialist hospitals in Ekiti State. The doctors (60 of them) were purposively and proportionately selected from the population while simple random sampling techniques was adopted in selecting 490 Nurses, making a total of 550 samples. A self-structured questionnaire titled: Cases and Causes of Maternal Mortality (CCMM) was used for data collection which were analysed using descriptive statistics of frequencies and inferential statistics of Pearson Product Moment Correlation (PPMC) was also used to test the hypotheses at 0.05 level of significance.

\author{
Results and Discussion \\ Descriptive Analyses \\ Question 1: To what extent do cases of maternal mortality occur in Ekiti State?
}


Table 1: Cases of Maternal Mortality in Ekiti State

\begin{tabular}{|l|l|l|l|l|l|l|l|}
\hline S/N & Items & SA & A & D & SD & Mean & Decision \\
\hline 1. & $\begin{array}{l}\text { There are cases of maternal } \\
\text { mortality in Ekiti State }\end{array}$ & $\begin{array}{l}500 \\
(90.9 \%)\end{array}$ & $\begin{array}{l}50 \\
(9.1 \%)\end{array}$ & $0(0)$ & $0(0)$ & 3.91 & Agreed \\
\hline 2. & $\begin{array}{l}\text { Maternal mortality cases are high } \\
\text { in Ekiti State }\end{array}$ & $\begin{array}{l}116 \\
(21.1 \%)\end{array}$ & $\begin{array}{l}108 \\
(19.6 \%)\end{array}$ & $\begin{array}{l}252 \\
(45.8 \%)\end{array}$ & $\begin{array}{l}74 \\
(13.5 \%)\end{array}$ & 2.50 & Agreed \\
\hline 3. & $\begin{array}{l}\text { Maternal death are not commonly } \\
\text { reported in Ekiti state }\end{array}$ & $\begin{array}{l}98 \\
(17.8 \%)\end{array}$ & $\begin{array}{l}100 \\
(18.2 \%)\end{array}$ & $\begin{array}{l}250 \\
(45.5 \%)\end{array}$ & $\begin{array}{l}102 \\
(18.5 \%)\end{array}$ & 2.35 & Disagreed \\
\hline 4. & $\begin{array}{l}\text { Women die daily from pregnancy } \\
\text { related complication in Ekiti State }\end{array}$ & $\begin{array}{l}108 \\
(19.6 \%)\end{array}$ & $\begin{array}{l}120 \\
(21.8 \%)\end{array}$ & $\begin{array}{l}190 \\
(34.5 \%)\end{array}$ & $\begin{array}{l}132 \\
(24.1 \%)\end{array}$ & 2.37 & Disagreed \\
\hline 5. & $\begin{array}{l}\text { One out of ten women death are } \\
\text { pregnancy related }\end{array}$ & $\begin{array}{l}206 \\
(37.5 \%)\end{array}$ & $\begin{array}{l}198 \\
(36 \%)\end{array}$ & $\begin{array}{l}80 \\
(14.5 \%)\end{array}$ & $66(12 \%)$ & 2.99 & Agreed \\
\hline 6. & $\begin{array}{l}\text { There is prolonged obstructed } \\
\text { labour that often leads to maternal } \\
\text { mortality }\end{array}$ & $\begin{array}{l}250 \\
(45.5 \%)\end{array}$ & $\begin{array}{l}206 \\
(37.5 \%)\end{array}$ & $\begin{array}{l}50.1 \%) \\
(94)\end{array}$ & 3.20 & Agreed \\
\hline 7. & $\begin{array}{l}\text { Ekiti is rank high in maternal } \\
\text { mortality rate in south west } \\
\text { Nigeria. }\end{array}$ & $\begin{array}{l}108 \\
(19.6 \%)\end{array}$ & $\begin{array}{l}252 \\
(45.8 \%)\end{array}$ & $\begin{array}{l}74.5 \%) \\
(13.5 \%)\end{array}$ & $\begin{array}{l}116 \\
(21.1 \%)\end{array}$ & 2.64 & Agreed \\
\hline
\end{tabular}

The result presented in Table 1 revealed that many of the respondents indicated that there are cases of maternal mortality in Ekiti State as the mean responses were 3.91. The respondents agreed with the statement that: maternal mortality cases are high in Ekiti State (2.50),one out of ten women death are pregnancy related (2.99), prolonged obstructed labouroften leads to maternal mortality (3.20) and Ekiti is rank high in maternal mortality rate in south west Nigeria (2.64). However, respondents indicated that women die from pregnancy related complication in Ekiti State but not daily. The results imply that there are high cases of maternal mortality in Ekiti State.

Question 2: Does age of pregnant women contribute to maternal mortality in Ekiti State?

Table 2: Age of Pregnant Women and Maternal Mortality in Ekiti State

\begin{tabular}{|l|l|l|l|l|}
\hline S/N & Items & Mean & $\begin{array}{l}\text { Standard } \\
\text { Deviation }\end{array}$ & Decision \\
\hline 1. & Early childbearing leads to maternal deaths & 3.54 & 0.98 & Agreed \\
\hline 2. & $\begin{array}{l}\text { The body of under-age and adolescentsare not fully developed, } \\
\text { hence they suffer complications leading to maternal death }\end{array}$ & 3.12 & 0.93 & Agreed \\
\hline 3. & $\begin{array}{l}\text { Early marriage enhances early pregnancy which often leads to } \\
\text { obstructed labourand maternal death }\end{array}$ & 3.38 & 0.90 & Agreed \\
\hline 4. & $\begin{array}{l}\text { Women of old age are liable to suffer complications during } \\
\text { pregnancy }\end{array}$ & 3.10 & 0.89 & Agreed \\
\hline 5. & $\begin{array}{l}\text { Age of pregnant of women is a factor responsible to maternal } \\
\text { mortality }\end{array}$ & 3.65 & 0.86 & Agreed \\
\hline Grand Criterion & 3.36 & 0.91 & Agreed \\
\hline
\end{tabular}

The result of analysis presented in Table 2 revealed the age of pregnant women as a factor leading to maternal mortality in Ekiti State. The mean values and criterion mean value in the table indicated that many of the respondents agreed that age of pregnant women contribute to maternal mortality in Ekiti State.

Question 3: Does educational status of pregnant women contribute to maternal mortality in Ekiti State?

Table 3: Educational Status of Pregnant Women and Maternal Mortality in Ekiti State

\begin{tabular}{|l|l|l|l|l|}
\hline S/N & Items & Mean & $\begin{array}{l}\text { Standard } \\
\text { Deviation }\end{array}$ & Decision \\
\hline 1. & $\begin{array}{l}\text { Illiterate and uneducated pregnant women often suffer complications } \\
\text { during childbearing, thus leading to maternal deaths }\end{array}$ & 3.08 & 0.87 & Agreed \\
\hline 2. & $\begin{array}{l}\text { Lack of pregnant women's knowledge about nutrition, birth spacing } \\
\text { and contraception lead to maternal death }\end{array}$ & 3.11 & 0.84 & Agreed \\
\hline 3. & $\begin{array}{l}\text { Lack of education for pregnant women affects their health and } \\
\text { causescomplications during childbearing, thus leading to maternal } \\
\text { deaths. }\end{array}$ & 3.10 & 0.92 & Agreed \\
\hline 4. & $\begin{array}{l}\text { Women of good educational background are liable to avoid } \\
\text { complications during pregnancy }\end{array}$ & 3.21 & 0.97 & Agreed \\
\hline 5. & $\begin{array}{l}\text { Women's lack of education is one of the causes of high maternal } \\
\text { mortality in Ekiti State }\end{array}$ & 3.65 & 0.99 & Agreed \\
\hline Grand Criterion & 3.23 & 0.92 & Agreed \\
\hline
\end{tabular}


The result of analysis presented in Table 3 revealed educational status of pregnant women as a factor leading to maternal mortality in Ekiti State. The mean values and criterion mean value in the table are high which indicated that many of the respondents agreed that educational status of pregnant women contribute to maternal mortality in Ekiti State.

\section{Test of Hypotheses}

Hypothesis 2: There is no significant correlation between age of pregnant women and maternal mortality in Ekiti State.

Table 4: Correlation between Age and maternal mortality in Ekiti State

\begin{tabular}{|l|l|l|l|l|l|l|}
\hline Variable & N & Mean & SD & r-cal & r-tab & Sig (P) \\
\cline { 1 - 2 } & 550 & 2.89 & 0.63 & & & \\
\cline { 1 - 3 } Maternal Mortality & 550 & 2.76 & 0.74 & $0.63^{*}$ & 0.23 & 0.01 \\
\hline
\end{tabular}

$\mathbf{P}<\mathbf{0 . 0 5} \quad$ *Significant

The result of analysis presented in table 4 revealed that there was high correlation between age and maternal mortality in Ekiti state as $r_{\text {cal }}(0.63)$ was greater than $r_{\text {tab }}(0.23)$ and P-value $(0.01)$ less than 0.05 level of significance. This led to the rejection of hypothesis one. Hence, age is a significant correlate of maternal mortality in Ekiti state

Hypothesis 2: There is no significant correlation between educational status of pregnant women and maternal mortality in Ekiti State

Table 5: Correlation between educational status and maternal mortality in Ekiti State

\begin{tabular}{|l|l|l|l|l|l|l|}
\hline Variable & N & Mean & SD & r-cal & r-tab & Sig (P) \\
\cline { 1 - 4 } & 550 & 3.01 & 1.56 & & & \\
\cline { 1 - 5 } Maternal Mortality & 550 & 2.76 & 0.74 & & & \\
& & & & $0.82^{*}$ & 0.23 & 0.02 \\
\hline
\end{tabular}

\section{$\mathbf{P}<0.05 \quad$ *Significant}

The result of analysis presented in table 5 revealed that there was high correlation between educational status and maternal mortality in Ekiti state as $r_{\text {cal }}(0.82)$ was greater than $r_{\text {tab }}(0.23)$ and $P$-value $(0.02)$ less than 0.05 level of significance. This led to the rejection of hypothesis one. Hence, educational status is a significant correlate of maternal mortality in Ekiti state

\section{Discussion}

The finding of the study revealed that there are cases of maternal mortality in Ekiti State. Ekiti State is ranked high in maternal mortality rate in south west Nigeria. The study showed that one out of ten women's death in Ekiti State is pregnancy related and prolonged obstructed labour, that is maternal mortality. According to Etuk (2002) and Etuk, Etuk, Ekott\&Udoma (2000) maternal mortality cases is high because most births in Nigeria and Ekiti State in particular do not take place in hospitals and majority of women prefer to visit quark midwives in the churches, thus increasing the rate of maternal cases in the state.

This menace was attributed to certain factors such as age and educational status among others. This finding agrees with the study of Marmort\& Wilkinson (2006) that the influence of the level of education of womenand age are common causes of maternal mortality.

The finding of this study revealed that educational status is a correlate of maternal mortality in Ekiti state. It is believed that educated women have more understanding of the physiology of reproduction and are less disposed to accept the complications and risks of pregnancy as inevitable than illiterate or uneducated women (Oxaal\& Baden, 1996). The finding is therefore similar to the finding of Graczyk (2007) who stressed that, lack of education can affect health when it limits young women's knowledge about nutrition, birth spacing and contraception. It was then reported by Ogujuyigbe\&Liasu, (2007) that high level of education among women tends to reduce the rate of maternal mortality.

Another finding of the study was that age is a correlate of maternal mortality in Ekiti state. Age of a woman is important to determining the readiness of the physiology of the mother. Many maternal deaths occur because of early childbearing (Ufford and Menkiti, 2001). This is because the bodies of adolescent are not fully developed. Abdul ${ }^{\text {ee } A z i z ~(2008) ~ t h e r e f o r e ~ s u g g e s t e d ~ t h a t ~ a ~ w o m a n ~ s h o u l d ~ n o t ~ s t a r t ~ h a v i n g ~ c h i l d r e n ~ t o o ~ e a r l y ~ i n ~ l i f e ~}$ to avoid complications and reduce maternal mortality.

\section{Conclusion}

Based on the findings of the study, it was concluded that there is high maternal mortality cases in Ekiti state and it is as a result of poor educational status and early marriage with early pregnancy. This ordeal however is common in Ekiti State as a result, there is high occurrence of maternal mortality in the state. 


\section{Recommendations}

The study recommends the following;

1. More awareness should be created on the causes of maternal mortality by the government, NGOs and other health regulated agencies, hence reducing this menace of maternal death.

2. Pregnant women should be educated by health workers on how successfully handle pregnancy related cases during complications.

3. Adolescent should be orientated on the consequences of early pregnancy since they are the most victim of maternal cases.

\section{References}

Abdul"Aziz, I. (2008) "Health-Nigeria: Little progress on maternal mortality". Source:http://www.ipsnew.net/G:/health2/HEALth-NIGERIA.Retrieved August 9th, 2008.

Etuk, S.J., Etuk, I.S., Ekott, M.I.\&Udoma, E.J. (2000). Perinatal outcome in pregnancies booked for prenatal clinic but delivered outside health care facilities in Calabar, Nigera. ActaTropica, 75, 29-33.

Graczyk, K. (2007) “Adolescents maternal mortality: An Overlooked Crisis”.From advocates for youth. Source: http://www.advocatesfor youth.org/publication

Harrison, K.A.(2009). The struggle to reduce high maternal mortality in Nigeria. African Journal of Reproductive Health,13(3),9-19.

Idowu, A.E, Osinaike, M.O, \&Ajayi, M.P. (2011). Maternal health challenges and prospects for national development: A Study of Badagry Local Government, Lagos State. Gender and Behaviour, 9(20), 42244246

Jegede, A. S. (2010) African culture and health. Ibadan: BookWright Publishers.

Marmot, M.G \& Wilkinson R.D, Eds 2006. Social determinants of health. Oxford, England: Oxford University Press.

Ogujuyigbe, P. O. \&Liasu, A. (2007) Perception and Health-seeking behaviour of Nigerian women about pregnancy-related risks: strategies for improvement. Journal of Chinese Clinical Medicine, 2 (11).643-654.

Oxaal, Z. \& Baden, S. (1996). Challenges to women's reproductive health: Maternal mortality. Report challenges to women reproductive health: Maternal mortality. Report prepared at the request of the social development department: Department of Oversea Development (DFID), UK.

Shah, I.H., Say L,. (2007) Maternal mortality and maternity care from 1990-2005: Uneven but Important Gains Reproductive Health Matters, Maternal Mortality and Morbidity: Is Pregnancy Getting Safer for Women? Reproductive Health Matters, 15,(30)17-27

Ufford, J. \&Menkiti, M. (2001) Delivery care is key for maternal survival: a story of two states in Nigeria Source: Population reference bureau. http:prb.org/Articles/2001/. Retrieved August, 2008.

World Health Organization, (2008). Making pregnancy safer: Maternal mortality and morbidity case review. Retrieved from; http//www.euro.who.int/infopages. August, 2008. 